\title{
Numerical modeling of the soil structure interaction during sinkholes.
}

\author{
M. Caudron, F. Emeriault \& R. Kastner \\ URGC Géotechnique, INSA de Lyon, VILLEURBANNE France \\ M. Al Heib \\ INERIS - LAEGO, Parc de Saurupt, NANCY FRANCE
}

ABSTRACT: This article focuses on the simulation of soil-structure interactions during a sinkhole by the use of a coupled numerical approach. The 2D model uses a Finite Difference computer code coupled with a Distinct Elements code (FLAC ${ }^{2 \mathrm{D}}$ and $\mathrm{PFC}^{2 \mathrm{D}}$ from Itasca Consulting Group) to optimize the performances of both softwares.

\section{INTRODUCTION}

Sinkholes are caused by natural or man-made cavities. The very sudden nature of this phenomenon may be damaging for the buildings and endangers the life of the population. The soil-structure interactions occurring during this phenomenon are not well understood. The commonly employed approach (in which the soil movements obtained in greenfield condition are applied to a structure) is not satisfying.

The main purpose of this paper is the presentation and the validation of a numerical model allowing a satisfying modeling of the soil-structure interactions during this phenomenon (Figure 1). Two codes are used jointly: FLAC $^{2 D}$ uses the Finite Differences Method whilst PFC $^{2 \mathrm{D}}$ is based on the Distinct Element Method. The results obtained in greenfield condition will be compared with those taking into account a building on the ground surface. Moreover a relevant comparison can be made between this numerical simulation and the results of an experimental campaign carried out on a small-scale model, illustrated by Figure 1 (For more details on this experimentation, the reader can refer to Caudron et al. 2006).

\section{THE CASE STUDY}

The experimental small-scale model uses a geometric scale of $1 / 40$ to model a $10 \mathrm{~m}$ wide and $2 \mathrm{~m}$ high gallery with a $8 \mathrm{~m}$ thick cover. It corresponds to the usual dimensions of the Parisian quarries that are responsible for several disorders each year. The soil mass modeled is $30 \mathrm{~m}$ wide and $20 \mathrm{~m}$ high.
The ground cover is composed of several different layers that can be roughly considered as two homogenous layers from a mechanical point of view: a $6 \mathrm{~m}$ thick cohesionless material overlies a $2 \mathrm{~m}$ thick cohesive layer. Their mechanical characteristics are presented in Table 1. In the small scale physical model, the cohesion of the material is reproduced by the addition of an aqueous solution of glue to cohesionless metallic Schneebeli rods Caudron et al. 2006.

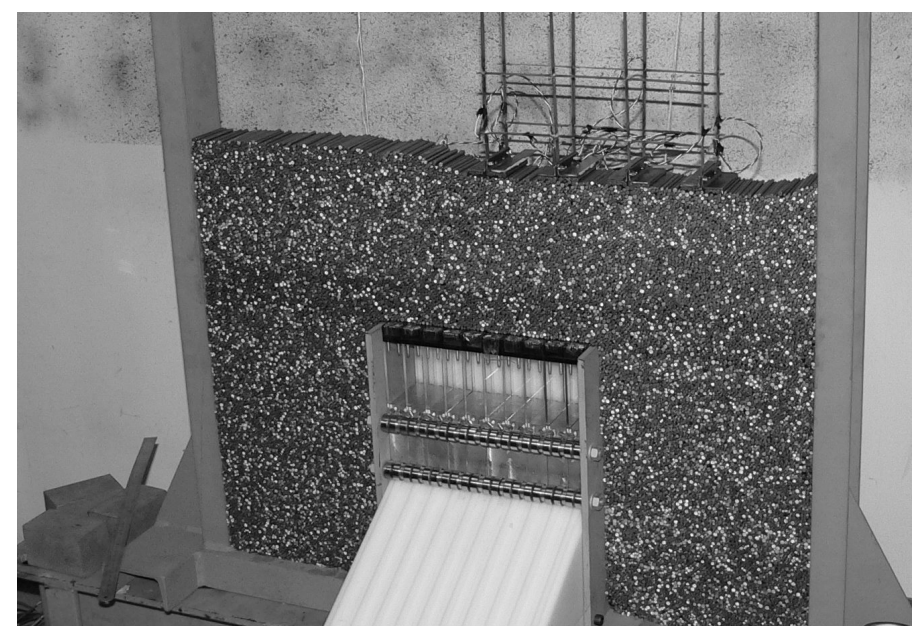

Figure 1. Laboratory small-scale model.

The structure corresponds, with a 1/40 scaling factor, to a dwelling with three spans and two stories. Its total width is $10 \mathrm{~m}$, each story is $2.7 \mathrm{~m}$ high and it comprises a crawl space of $1.2 \mathrm{~m}$ in height (more details are given in Table 2). The left foundation is located directly above the center of the cavity. The structure is made of standard steel beams and columns and the applied payloads are determined in order to induce stresses on the foundations corresponding to the Serviceability Limit State. 


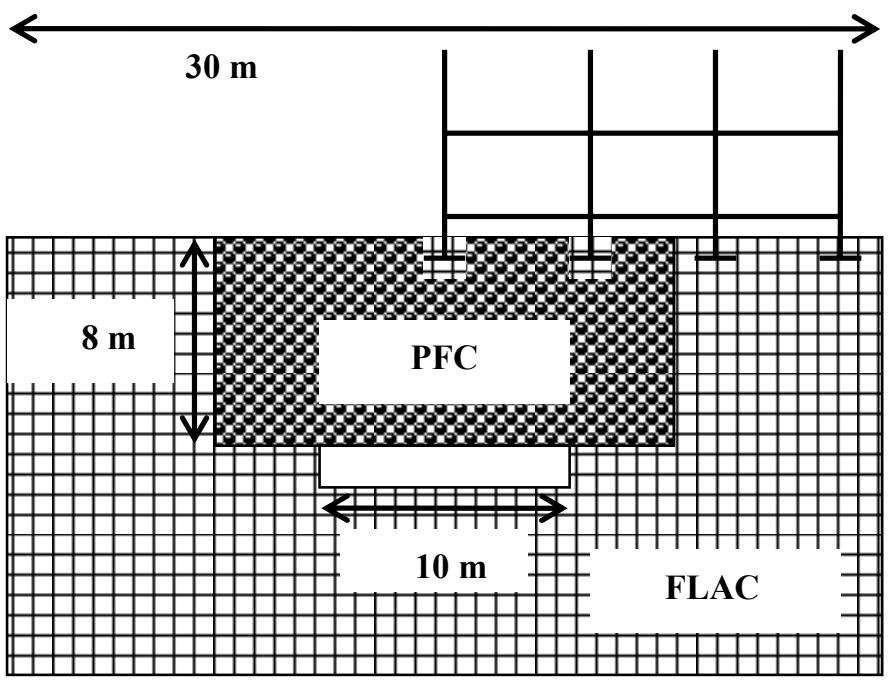

Figure 2. Schematic view of the coupled model.

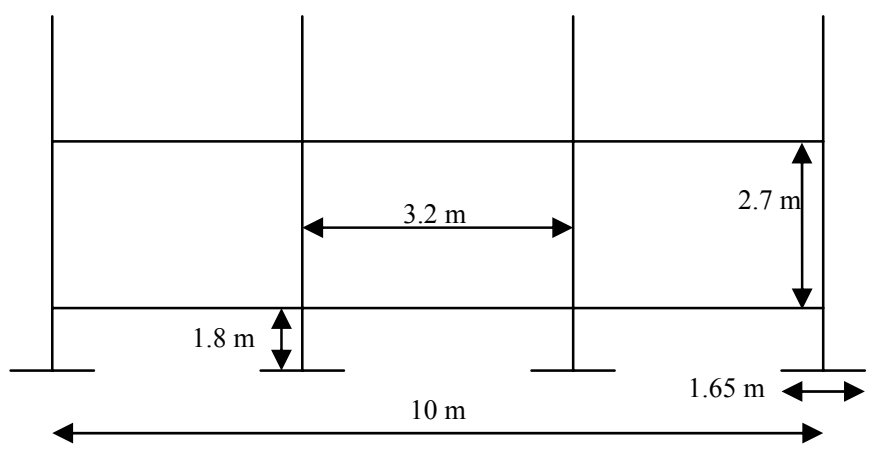

Figure 3. Dimensions of the considered building.

The creation of the cavity follows a simple procedure and five steps are necessary to obtain the 10 $m$ total opening. The first step implies the creation of a small cavity: $2 \mathrm{~m}$ in width with the nominal $2 \mathrm{~m}$ height. Then, for each of the four following steps, one meter of cavity is opened on each side of the cavity until the final width is reached.

Table 1. Soil properties of the documented case study.

\begin{tabular}{lcc}
\hline & Granular soil & Cohesive soil \\
\hline $\mathrm{E}(\mathrm{MPa})$ & $50-100$ & $50-100$ \\
$\nu$ & 0.30 & 0.30 \\
$\rho\left(\mathrm{kg} / \mathrm{m}^{3}\right)$ & 2200 & 2200 \\
$\varphi\left({ }^{\circ}\right)$ & $\sim 26$ & $\sim 26$ \\
$\mathrm{c}(\mathrm{kPa})$ & 0 & $\sim 100$ \\
\hline
\end{tabular}

Table 2. Characteristics of the building.

\begin{tabular}{lc}
\hline Beam length & $3.2 \mathrm{~m}$ \\
Foundation width & $1.65 \mathrm{~m}$ \\
Story height & $2.7 \mathrm{~m}$ \\
Crawl space & $1.2 \mathrm{~m}$ \\
Element section $\left(\mathrm{m}^{2} / \mathrm{m}\right)$ & $0.051 \mathrm{~m}^{2}$ \\
Element inertia $\left(\mathrm{m}^{4} / \mathrm{m}\right)$ & $60.410^{-4} \mathrm{~m}^{4}$ \\
Number of spans & 3 \\
\hline
\end{tabular}

\section{THE COUPLED NUMERICAL MODEL}

The use of a coupled numerical approach based on two different numerical schemes (in the present case DEM and FDM) presents two main advantages:

On one hand, it is possible to refine the description of the behaviour of a soil mass in certain locations where large strains, displacement or shear stresses will develop (in the present case, the whole soil mass located above the cavity and in the vicinity of the structure).

On the other hand, it can reduce computation times by using a faster numerical resolution algorithm (such as the Finite Difference Method) in the rest of the soil where only small deformations will appear and for the modeling of the building and structural elements such as beams.

Figure 2 shows a schematic view of the coupled model that uses FLAC ${ }^{2 \mathrm{D}}$ and $\mathrm{PFC}^{2 \mathrm{D}}$ (both softwares have been developed and are commercialized by Itasca Consulting Group - 2005).

FLAC $^{2 D}$ uses a Finite Difference formulation applied to a continuum, whereas $\mathrm{PFC}^{2 \mathrm{D}}$ is based on the Distinct Elements Method. They can exchange informations with one another through a socket connection, in particular the data required to satisfy at any step of the calculation the interface conditions between the FD mesh and the particle assembly. The simple coupling procedure illustrated on Figure 4 can be strictly followed in a "simple" case, i.e. when no loss or creation of contact can occur between the particles and the border elements.

Nevertheless, in the present case, it is necessary to be able to take into account major modifications in the geometry of the border elements (when the cavity is gradually created by deleting FLAC $^{2 \mathrm{D}}$ grid elements) and also losses or creations of contacts of the border elements with moving particles.

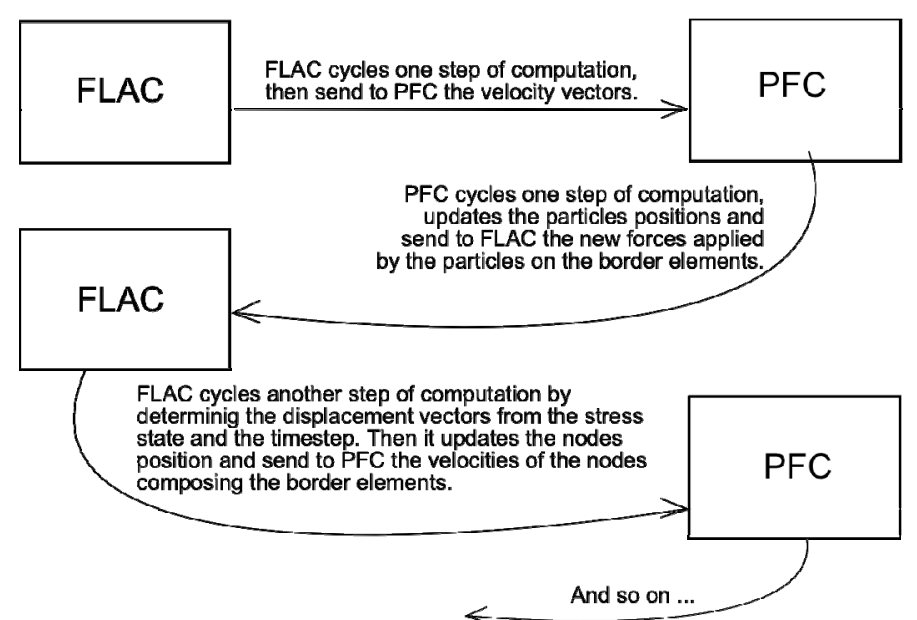

Figure 4. Basis for the FLAC-PFC coupling scheme.

Therefore, a specific scheme has been developed. This scheme includes the basic one (presented in Figure 4) and determines automatically when it is necessary to update the list of slave particles ( $\mathrm{PFC}^{2 \mathrm{D}}$ particles linked to FLAC $^{2 \mathrm{D}}$ border elements).

Step 1: The user specifies a total number $X$ of calculation cycles to compute.

Step 2: A specific Fish function determines the maximum value of the particle velocities in the assembly, $V_{\max }$. Given the smallest particle radius in the assembly, the program then determines the number of cycles $x$ that can be safely achieved: 
$x=R_{\min } / V_{\max }$

In Equation 1, it is assumed that in $x$ cycles the displacement of the fastest particle can not exceed a maximum value arbitrarily taken equal to the smallest particle radius in the assembly, otherwise the list of slave particles has to be updated.

Step 3: $y$ calculation cycles are computed using the coupling scheme detailed above where $y$ is the minimum of $x$ and $X$.

Step 4: PFC $^{2 D}$ frees the slave particles, get the new border elements list from FLAC ${ }^{2 \mathrm{D}}$ and defines the new list of slaves particles.

Step 5: The procedure goes back to Step 2 after replacing $X$ by $X-y$. The loop is followed until the total number of calculation cycles $X$ introduced in Step 1 is achieved.

When the FLAC ${ }^{2 \mathrm{D}}$ grid has to be modified during calculations, the same scheme is used: the required modifications of the border elements and their geometry are performed between Steps 4 and 5 .

Between two stages of the creation of the cavity, stabilization of the soil is ensured: the maximum particle velocity in the assembly should be smaller than $10^{-11} \mathrm{~m} /$ calculation cycle.

Finally, Figure 2 shows that the structure represented by FLAC ${ }^{2 \mathrm{D}}$ beam elements is not directly in contact with $\mathrm{PFC}^{2 \mathrm{D}}$ particles but via small FLAC ${ }^{2 \mathrm{D}}$ grids. This modeling enables to cope with the limitation of the coupling scheme to the exchange of data between $\mathrm{PFC}^{2 \mathrm{D}}$ particles and FLAC ${ }^{2 \mathrm{D}}$ grid elements

\section{INTERPARTICLE CONTACT PARAMETERS $\left(\mathrm{PFC}^{2 \mathrm{D}}\right)$}

The determination of the interparticle contact parameters required by the DEM and $\mathrm{PFC}^{2 \mathrm{D}}$ is based on the results of biaxial tests $\left(\mathrm{q}-\varepsilon_{1}\right.$ and $\varepsilon_{\mathrm{v}}-\varepsilon_{1}$ curves) performed on the cohesionless and cohesive materials (Caudron et al. 2006). The main parameters describing the behaviour of the particles are:

- $k_{n}$ and $k_{s}$, the normal and tangent stiffness of the contact between two particles,

- fric, the intergranular coefficient of friction.

- $c \_n$ and $c \_s$, the normal and tangent strength of the contact bonds used to represent the overall soil cohesion (Potyondy \& Cundall 2004).

For the sake of simplicity, two assumptions are made reducing to 3 the number of independent parameters: the ratio $k_{n} / k_{s}$ is supposed to be equal to 2 and the ratio $c \_n / c_{-} s$ to 1 .

Two sets of parameters are determined (Table 3 ), respectively for the granular soil (standard metallic Schneebeli rods assembly) and for the cohesive material (Schneebeli rods soaked in an aqueous glue solution). Figure 5 gives an example of the results obtained for the cohesive soil.
The evolution of the deviatoric stress during biaxial compression is generally accurately reproduced, in particular the initial modulus and the deviatoric strength (as shown in Figure 5). The comparison of the experimental and computed volumetric strains presents more discrepancies. The DEM and its implementation in PFC $^{2 \mathrm{D}}$ lead to an initial contractancy of the sample under shear stress whereas in the experiments dilatancy is observed even in the early stages of the loading. Nevertheless, after 1 or $2 \%$ of axial strain, the same dilatancy angle is observed.

Table 3. PFC parameters.

\begin{tabular}{lcc}
\hline Parameters & $\begin{array}{c}\text { Granular } \\
\text { material }\end{array}$ & $\begin{array}{c}\text { Cohesive } \\
\text { material }\end{array}$ \\
\hline $\mathrm{k}_{\mathrm{n}}(\mathrm{MN} / \mathrm{m})$ & 16.0 & 16.0 \\
$\mathrm{k}_{\mathrm{s}}(\mathrm{MN} / \mathrm{m})$ & 8.0 & 8.0 \\
Fric & 0.50 & 0.45 \\
Density & 7.85 & 7.85 \\
c_n \& c_s $(\mathrm{N})$ & 0 & 1000 \\
\hline
\end{tabular}

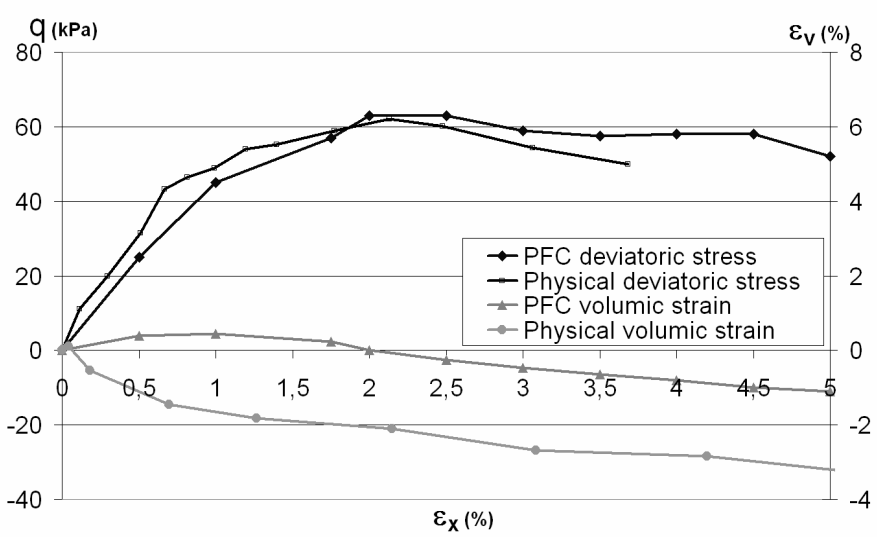

Figure 5. Deviatoric stress and volumetric strain for the cohesive soil (biaxial test performed with $50 \mathrm{kPa}$ confining stress).

\section{SIMULATIONS AND RESULTS}

Two subsidence tests have been performed:

- one corresponds to greenfield conditions, i.e. without any structure, and will be considered as a reference,

- in the second one, the small scale model of building is positioned at ground level, with its left foundation located directly above the center of the cavity, in order to observe soilstructure interaction effects.

Deck (2002) showed that several main parameters are representative of the potential damage to a building induced by the soil movements induced by sinkholes. They include the maximum subsidence or vertical displacement, the shape of the settlement trough, the differential horizontal displacements and the slope of the ground surface in the vicinity of the building (or where it should be positioned if one explicitly takes soil-structure interaction). 


\subsection{The greenfield case}

The cavity is created in five steps, it remains stable as it is observed in experimental test. The cohesive layer is then locally weakened in order to cause failure. Weakening is induced in the middle of the cavity roof by simultaneously applying a reduction factor to $c \_n$ and $c \_s$ the normal and tangential strength limits of the contact bonds in this area. When the crack development reaches a critical state, collapse appears in a very brutal manner and total failure of the cavity is observed.

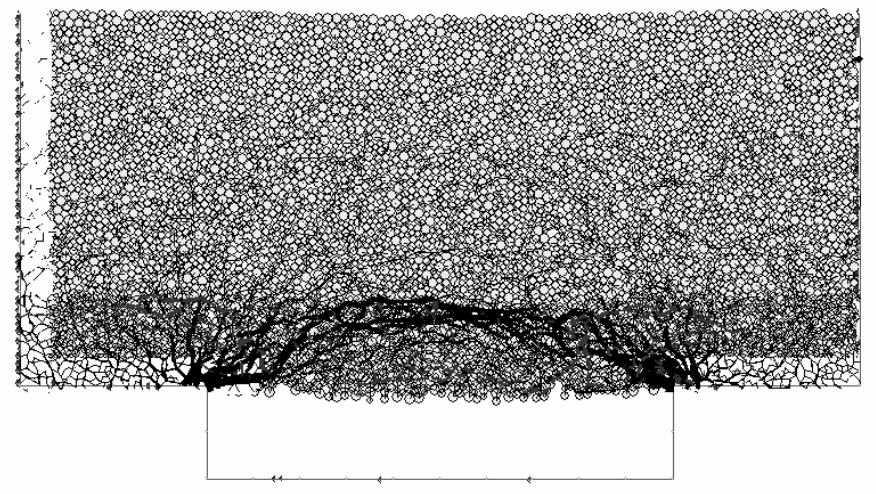

Figure 6. Stress distribution in the soil mass.

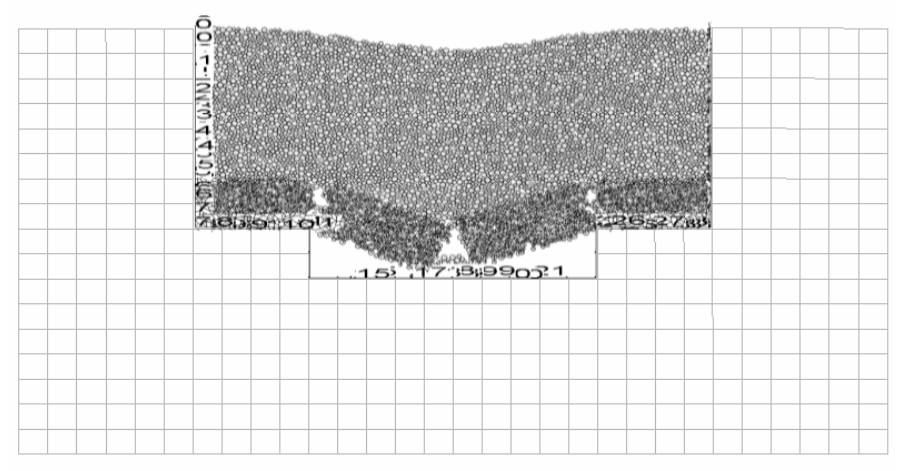

Figure 7. Final state after failure for the greenfield test.

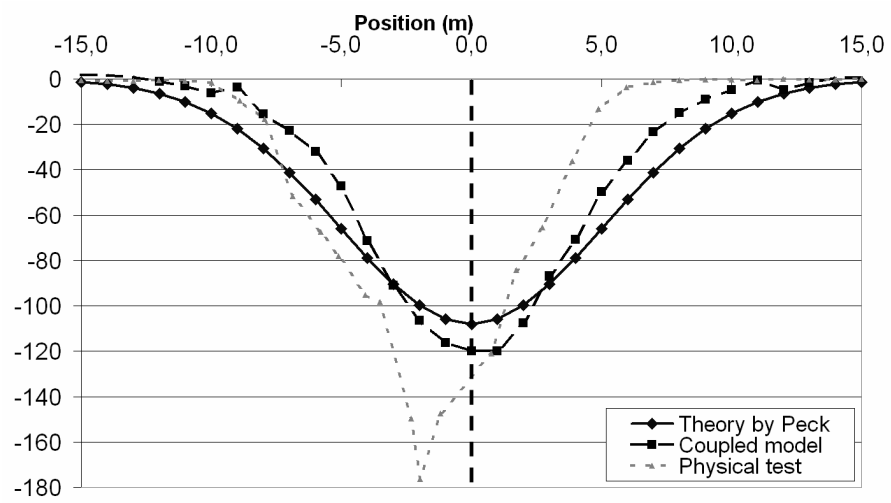

Subsidence $(\mathbf{c m})$

Figure 8. Subsidence troughs for the FLAC-PFC model, the physical test and the Peck approach.

Figure 6 illustrates the stress distribution at the end of the creation of the cavity when a stable state is obtained. The stress concentration on the vertical walls of the cavity is obvious, as the presence of tensile stress in the central lower part of the stiff bench and in its upper part above the side walls of the cavity.

Figure 7 shows the final state, i.e. after failure, and the induced ground surface deformation. The corresponding subsidence or settlement trough is presented on Figure 8 and compared with the results of the experimental test and with a semi-empirical approach.

The latter is a modified version of Peck's semiempirical approach proposed by Caudron et al. 2004 for rectangular shaped cavities. The total volume of the settlement trough is computed from the volume of the cavity multiplied by a factor depending on the expansion coefficient $K(K \approx 0.5$ in this particular case study):

$V_{\text {trough }}=\frac{1}{1+K} V_{\text {cavity }}$

An equivalent cavity radius $R_{e q}$ is also calculated from the trough volume. Caudron et al. 2004 have shown that this enables the computation of $i$, the distance from the center of the settlement trough to the point of inflexion using Oteo \& Sagaseta's empirical expression (1982).

$i=0.42 R_{e q}+0.525 H$

and $S_{\max }$ the maximum subsidence above the center of the cavity by:

$S_{\max }=\frac{V_{\text {trough }}}{2.51 \times i}$

where $H$ is the cavity cover.

Table 4. Geometric characteristics for the troughs in greenfield condition.

\begin{tabular}{lccc}
\hline Characteristic & $\begin{array}{c}\text { Physical } \\
\text { test }\end{array}$ & $\begin{array}{c}\text { Semi-empirical } \\
\text { approach }\end{array}$ & $\begin{array}{c}\text { FLAC-PFC } \\
\text { model }\end{array}$ \\
\hline $\mathrm{S}_{\max }$ & $176 \mathrm{~cm}$ & $108 \mathrm{~cm}$ & $120 \mathrm{~cm}$ \\
$\mathrm{I}$ & $\sim 3.5 \mathrm{~m}$ & $\sim 5 \mathrm{~m}$ & $\sim 4 \mathrm{~m}$ \\
$\%$ of $\mathrm{V}_{\text {cavity }}$ & $60 \%$ & $66 \%$ & $58 \%$ \\
$\begin{array}{l}\text { Maximum } \\
\text { slope }\end{array}$ & $39 \%$ & $13 \%$ & $24 \%$ \\
\hline
\end{tabular}

Table 4 summarizes the main parameters of the settlement troughs resulting from the experimental, semi-empirical and coupled numerical approaches. It appears that:

- the numerical simulation gives a better description of the overall volume of the settlement trough,

- the width of the predicted trough is smaller than that resulting from the semi-empirical approach and closer to the observed experimental value,

- therefore the maximum settlement and the maximum slope observed on the trough are in closer agreement with the experiments.

However, it must be noted that the failure mechanism observed in the physical test (shown on Figure 
9) is different from that considered in the numerical and semi-empirical approaches (leading to symmetric settlement trough). Only the left part of the cohesive layer felt into the cavity, the right part remained overhanging.

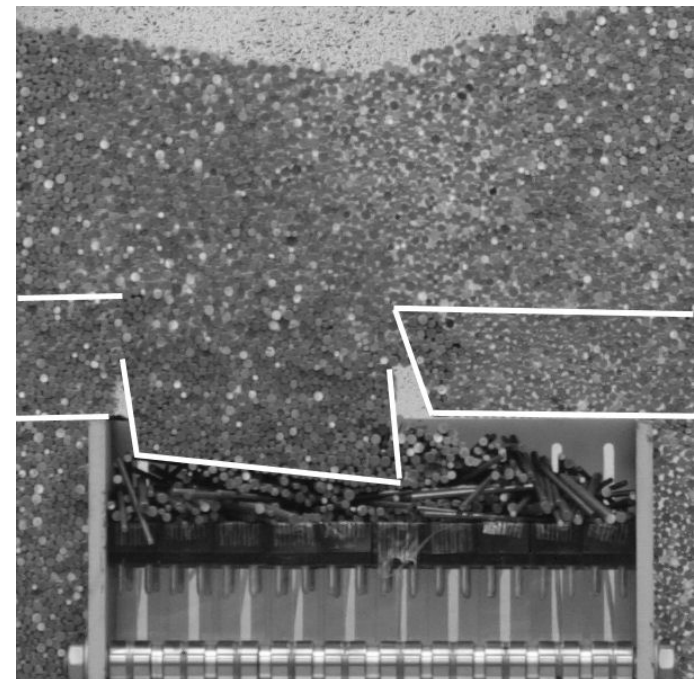

Figure 9. Partial failure during the small-scale physical test in greenfield condition.

\subsection{Soil-structure interaction}

The coupled model that explicitly considers the presence of a building at ground surface uses the same procedure for the cavity creation and the weakening of the cohesive layer. The final state reached is illustrated on Figure 10. The failure is quite similar to the one observed in greenfield conditions.

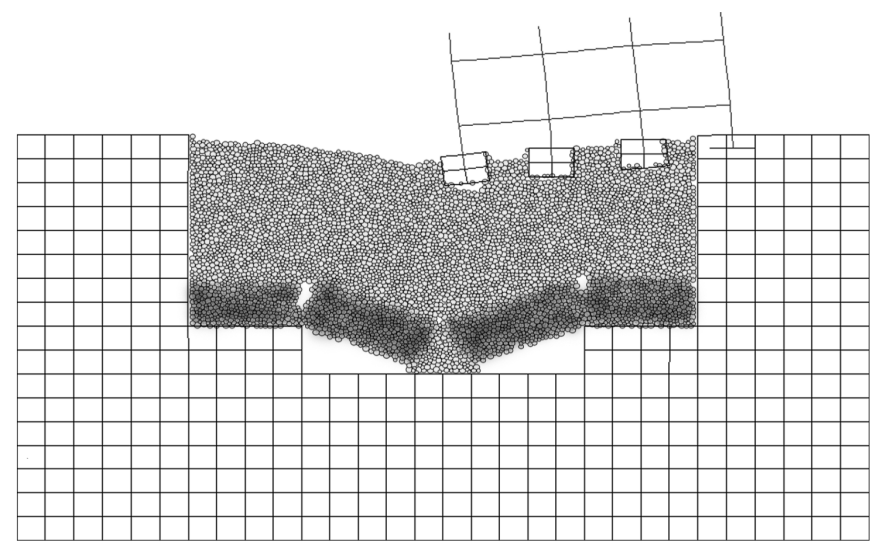

Figure 10. Final state for the model with the building.

It appears that the left foundation is not completely resting on the particles. A void is clearly visible under this foundation as well as in the upper part of the rigid bench directly above the cavity sidewalls.

The subsidence trough is plotted on Figure 11 with the position of the three foundations laying in the particles assembly. The results of the physical test with the structure on the ground surface are compared with the outcome of the coupled numerical simulations a) in greenfield condition and b) with the building. The main differences are located on the right part of the curves where the building model is situated. Table 5 summarizes the main characteristics of the observed and computed settlement troughs.

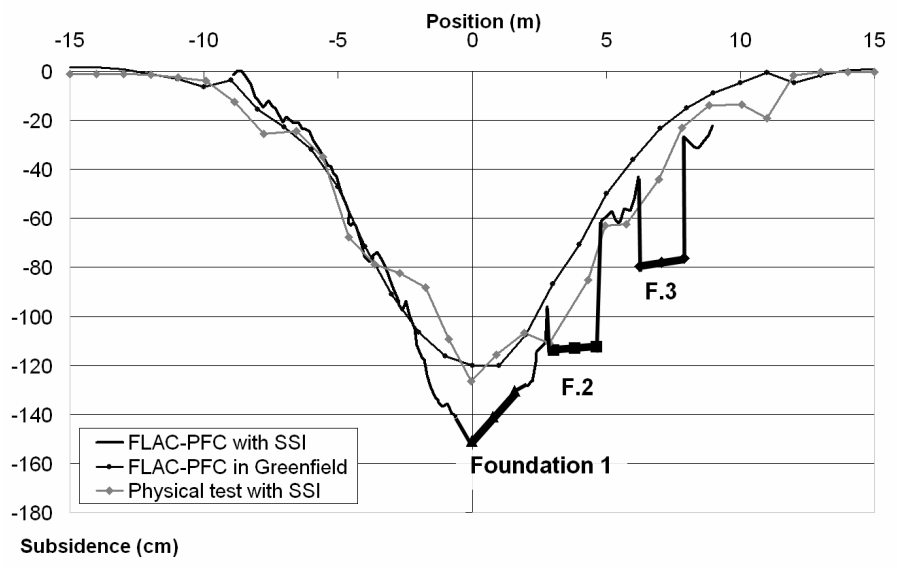

Figure 11. Subsidence trough for the computation with the soil-structure interaction.

The computed trough volumes are smaller than the average value obtained from the physical tests. The values of $S_{\max }, i$ and the maximum slope predicted by the numerical model with structure are closer to the experimental results than the greenfield simulation. Both numerical models predict a maximum differential settlement between foundation 2 and 3, i.e. in the central span. However, in the case with structure, the predicted maximum slope is smaller than that observed value in the greenfield case and also smaller than the experimental value. This can be partly explained by the stiffness of the link between the right foundation (foundation 4) with the FLAC ${ }^{2 \mathrm{D}}$ grid (Figure 10).

Table 5. Quantitative results for the models with the building.

\begin{tabular}{lccc}
\hline Characteristic & $\begin{array}{c}\text { Physical test } \\
\text { with SSI }\end{array}$ & $\begin{array}{c}\text { FLAC-PFC } \\
\text { in greenfield }\end{array}$ & $\begin{array}{c}\text { FLAC-PFC } \\
\text { with SSI }\end{array}$ \\
\hline $\mathrm{S}_{\max }$ & $127 \mathrm{~cm}$ & $120 \mathrm{~cm}$ & $151 \mathrm{~cm}$ \\
$\mathrm{i}$ & $\sim 4.5 \mathrm{~m}$ & $\sim 4 \mathrm{~m}$ & $\sim 4 \mathrm{~m}$ \\
\% of $\mathrm{V}_{\text {cavity }}$ & $64 \%$ & $58 \%$ & $54 \%$ \\
Maximum slope & $35 \%$ & $24 \%$ & $34 \%$ \\
Maximum slope & $\sim 18 \%$ & $\sim 15.3 \%$ & $\sim 11 \%$ \\
$\begin{array}{l}\text { on the building } \\
\text { Situation (span) }\end{array}$ & $\mathrm{F}_{2}-\mathrm{F}_{3}$ & $\mathrm{~F}_{2}-\mathrm{F}_{3}$ & $\mathrm{~F}_{2}-\mathrm{F}_{3}$ \\
\hline
\end{tabular}

Figure 12 illustrates the impact of the structure on the distribution of the horizontal displacements: the numerical simulation roughly reproduces the reduction in horizontal displacements in the vicinity of the structure and the dissymmetry of the distribution. On the left part of the trough, the experimental and numerical results almost coincide with the greenfield semi-empirical approach

The induced stresses and efforts in the structure may be analyzed from a qualitative point of view. It appears that the two left columns concentrate the maximum efforts and more particularly their lower 
part (between the foundation and the first floor): an increase of bending moments of about $13 \mathrm{kN} . \mathrm{m}$ is observed. Moreover, the opposite signs of the moments indicate that the left span is subjected to horizontal compression during the test. This is confirmed by comparing the horizontal displacement vectors on Figure 12.

For the horizontal elements of structure, the coupled numerical approach predicts that the maximum induced bending moment is localized in the central span of the lower floor (more exactly near the junction with the third column). Similar results have been obtained in the physical test: it appeared that the maximum stress (measured by strain gauges) is located in the column 1 and 2 and in the span $F_{1}-F_{2}$ of the lower beam.

Finally, during the simulation, the total force acting on the sidewalls and away from the cavity can be computed. Figure 13 clearly shows that each step of the creation of the cavity leads to an increase of this vertical force and that the effect of the stress redistribution is limited a 2 to $3 \mathrm{~m}$ thick zone from the sidewalls. The computed values presented in Figure 13 are relevant with the conclusions of the smallscale test (Caudron et al. 2006).

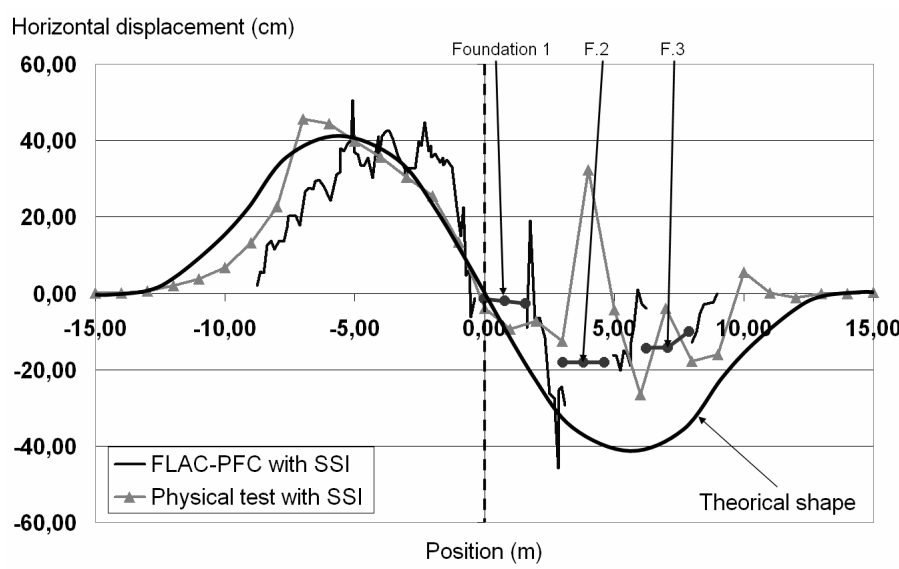

Figure 12. Horizontal displacement profiles (compared with the semi-empirical approach in greenfield condition).

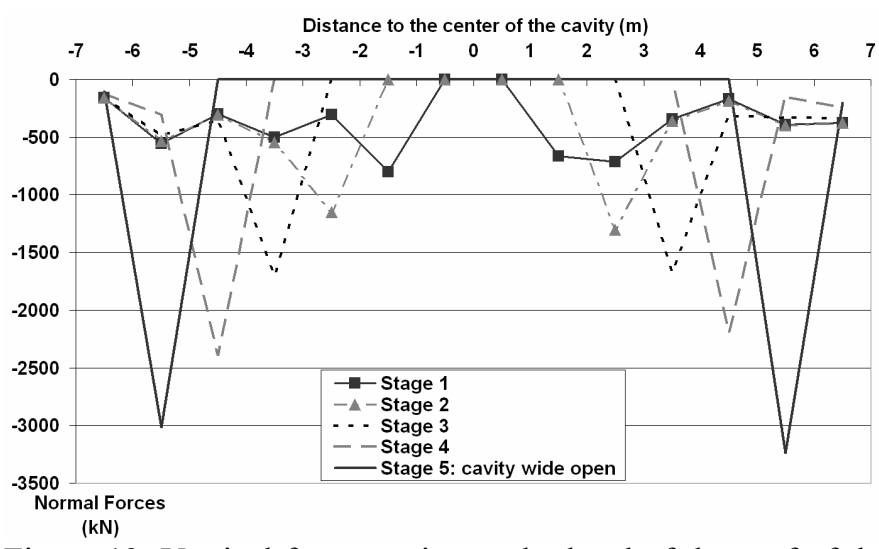

Figure 13. Vertical forces acting at the level of the roof of the cavity.

Nevertheless, it should be mentioned that in both numerical and physical tests, the walls of the cavity are largely stiffer than the soil which is generally not true in real situations where the deformability of the material constituting the walls leads to smaller stress concentration.

\section{CONCLUSION AND PROSPECTS}

This paper demonstrates that a coupled FLAC ${ }^{2 \mathrm{D}}$ $\mathrm{PFC}^{2 \mathrm{D}}$ approach can be used to reproduce in a satisfying manner the soil-structure interaction phenomena induced by sinkholes.

Further research should improve the ability of the model to quantitatively describe the volume of the subsidence trough (smaller than the experimental values in the present analysis). Even if the efforts induced in the structure by the soil movements are complex, the coupled approach gives qualitatively similar results to the experimental observations. An in-depth analysis of the stresses and efforts induced in the structure is required to the global understanding of the phenomenon.

After improvement, the $\mathrm{FLAC}^{2 \mathrm{D}}-\mathrm{PFC}^{2 \mathrm{D}} \mathrm{nu}-$ merical model will be used for parametric studies in order to determine the influence of each parameters of the problem: geometry of the cavity and position with respect to the building, mechanical characteristics of the soil mass and nature of the structure.

\section{ACKNOWLEDGEMENTS}

The authors would like to thank the French Ministry of Environment and Sustainable Development for partial funding of INERIS and its research project DRS02.

\section{REFERENCES}

Caudron M., Mathieu P., Emeriault F. et Al Heib M. 2004. Effondrement de cavités souterraines et interaction avec les ouvrages en surface : approche expérimentale sur modèle analogique bidimensionnel, Journées Nationales de la Géotechnique et de la Géologie pour l'Ingénieur, Lille, 28-30 June 2004, 435-442.

Caudron M., Emeriault F., Kastner R. et Al Heib M. 2006. Sinkhole and soil-structure interactions: Development of an experimental model. International Conference on Physical Modeling in Geotechnics, Hong-Kong, 04-06 August 2006.

Deck O. 2002 : Etude des conséquences des affaissements miniers sur le bâti. Propositions pour une méthodologie d'évaluation de la vulnérabilité du bâti. PhD. Thesis, INPL, Nancy, 241p.

Itasca Consulting Group 2005. PFC ${ }^{2 \mathrm{D}}$ Manuals (Particles Flow Code in 2 Dimensions), Version 3.10, ICG, Minneapolis, Minnesota.

Oteo C.S., Sagaseta C. 1982. Prediction of settlements due to underground openings, Int. Symp. On Num. Meth. In Geomechanics, Zurich, 13-17 September, 653-659.

Potyondy D.O., Cundall P.A. 2004. A bonded-particle model for rock. International Journal of Rock Mechanics \& Mining Sciences, 41:1329-1364. 